\title{
Tributação da Energia no Brasil: necessidade de uma preocupação constitucional extrafiscal e ambiental $^{1}$
}

\author{
Energy Taxation in Brazil: the need for a constitutional extrafiscal and \\ environmental concern
}

\author{
Luiz Alberto Blanchet \\ Pontifícia Universidade Católica do Paraná, PR, Brasil \\ Edson Luciani de Oliveira \\ Pontifícia Universidade Católica do Paraná, PR, Brasil
}

\begin{abstract}
Resumo: O objetivo deste estudo é examinar como é e como poderia ser tratada a tributação da energia com vistas à proteção ambiental pela extrafiscalidade. A arrecadação é fundamental, mas em Estados Democráticos modernos, a tributação constitucional já se volta para aspectos ambientais, algo que não ocorre no Brasil. $\mathrm{O}$ método que se utilizou partiu da Constituição e dedutivamente, em razão da própria Constituição, da doutrina, da situação fiscal brasileira e das experiências internacionais, concluiu-se que é necessário repensar o atual sistema constitucional tributário brasileiro para que possam ser inseridos novos elementos extrafiscais com preocupações ambientais, principalmente quando se trata da energia.
\end{abstract}

Palavras-chave: Tributação. Energia. Extrafiscalidade.

${ }^{1}$ Recebido em: 24/04/2013

Revisado em: 26/05/2013

Aprovado em: 30/11/2013

\begin{abstract}
The objective of this study is to examine how it is and how it could be treated energy taxation with a view to environmental protection by extrafiscality. The collection is essential, but in modern Democratic States, the constitutional taxation already turns to aspects of environmental, something that does not occur in Brazil. The method used came from Constitution and deductively, by reason of the Constitution itself, the doctrine, the Brazilian fiscal situation and international experiences, it was concluded that there is a need to rethink the current constitutional Brazilian tax system so that they can be inserted new elements no same with environmental concerns, especially in dealing with energy.
\end{abstract}

Keywords: Tax. Energy. Extrafiscality. 


\section{Introdução - Objetivo e Metodologia Do Estudo}

O objetivo deste estudo é examinar como é e como poderia ser tratada a tributação da energia no Brasil com vistas à proteção ambiental pela extrafiscalidade.

O tema é justificado porque vários países, notadamente europeus, desde a década de 1990, vêm implementando as chamadas reformas fiscais verdes e a energia é tema obrigatório para ser analisado em qualquer reforma tributária ambiental. Os relatórios fornecidos pelas agências internacionais apontam dificuldades, mas também aspectos positivos, que poderiam ser aproveitados pelo Brasil com as devidas adequações. Constata-se que, pelo menos do ponto de vista constitucional brasileiro, existe pouca preocupação com a tributação da energia e seus impactos ambientais. Neste estudo foram utilizados dados estatísticos e históricos, visitando as experiências e as normas de vários países, tendo a certeza de que a argumentação jurídica hoje passa pela análise de casos concretos e não pode ficar adstrita a concepções apenas formais, sem conexão com a concretude do fato. Este trabalho tem uma visão propositiva do Direito e não apenas descritiva, pois, pretende-se mostrar que a análise jurídica é preponderante, mas não pode ficar imersa em pessimismos, argumentos e projeções distantes da realidade das experiências já catalogadas em outros países, úteis, adaptáveis ao caso brasileiro e de suma importância, particularmente, relacionadas ao Direito Ambiental, ramo jurídico que não tolera discurso vago e busca permanentemente elementos de concreta eficácia. A metodologia aqui empregada, desse modo, contará com elementos históricos, normativos, e será guiada por elementos que levarão a deduzir que hoje não existe uma preocupação constitucional tributária com o meio ambiente e que tal situação brasileira deveria ser repensada.

\section{Marcos Normativos e de Pensamento}

A energia merece destaque, uma vez que representa desenvolvimento, poder $^{2}$, soberania. Porém, a sua correta utilização pode trazer conse-

2 Ver Beder (2005). 
quências positivas para a sociedade e para a ecologia no contexto de uma Reforma Fiscal "Eco-nômica" como de forma interessante expôs Sterling (1998, p. 26), ao aproximar o tema aos objetivos da redução do alto nível de desemprego, da contaminação e do esgotamento dos recursos naturais. Não se pode negar que a carga tributária da energia no Brasil, desde seu ciclo de geração até o consumo, é relativamente alta, tendo-se em conta todos os tributos e encargos envolvidos. Qualquer proposta de reforma tributária, principalmente ligada à tributação da energia, deve levar em conta a existência não apenas dos impostos que serão aqui mencionados, mas também das taxas, das contribuições especiais, sociais, dos chamados tributos parafiscais, enfim, de todos os encargos ${ }^{3}$ relacionados às fontes e atividades ligadas à energia. $\mathrm{O}$ interesse é examinar se hoje a tributação considera aspectos ambientais e não somente econômicos relativos à energia. Antes de partir para este exame, importante destacar os dispositivos constitucionais e infraconstitucionais que tratam do assunto.

A atual Constituição Federal no seu Título VII, Da Ordem Econômica e Financeira, precisamente em seu Capítulo I, Dos Princípios Gerais da Atividade Econômica, estabelece:

Art. 170 A ordem econômica, fundada na valorização do trabalho humano e na livre iniciativa, tem por fim assegurar a todos existência digna, conforme os ditames da justiça social, observados os seguintes princípios:

$[\ldots]$

$\mathrm{VI}$ - defesa do meio ambiente;

E o artigo 225 da Constituição brasileira ainda prevê:

Art. 225 Todos têm direito ao meio ambiente ecologicamente equilibrado, bem de uso comum do povo e essencial à sadia qualidade

\footnotetext{
Sobre encargos no setor elétrico, por exemplo, ver página 8-9 do Informativo Tarifário - Energia Elétrica, publicado em maio de 2012. Brasília: Ministério das Minas e Energia, 2012. Disponível em: <http://www.mme.gov.br/mme/galerias/arquivos/acoes/Energia/ Resumo_Informativo_Portal_MME_maio_2012.pdf>. Acesso em: 29 mar. 2013.
} 
de vida, impondo-se ao Poder Público e à coletividade o dever de defendê-lo e preservá-lo para as presentes e futuras gerações.

Mas a proteção ambiental também encontra amparo na Lei $n$. 6.938/81, a qual dispõe sobre a Política Nacional do Meio Ambiente e, particularmente, deve ser destacado que a Política Nacional do Meio Ambiente tem por objetivo a preservação, melhoria e recuperação da qualidade ambiental propícia à vida, visando assegurar, no País $\left(\operatorname{artigo} 2^{\circ}\right.$ ) e que meio ambiente é o conjunto de condições, leis, influências e interações de ordem física, química e biológica, que permite, abriga e rege a vida em todas as suas formas e que a degradação da qualidade ambiental é a alteração adversa das características do meio ambiente (artigo $3^{\circ}$, I e II). No mesmo passo, deve ser citada a Lei n. 9.985/2000 que regulamenta o artigo 225, $\S 1^{\circ}$, da Constituição Federal (instituição do Sistema Nacional de Unidades de Conservação da Natureza). E para tratar da energia em particular deve ser mencionada a Lei n. 9.478/97, que dispõe sobre a política energética nacional (instituição do Conselho Nacional de Política Energética e a Agência Nacional do Petróleo) e as atividades relativas ao monopólio do petróleo (artigo $1^{\mathrm{o}}$, incisos I, II e IV que mencionam o interesse nacional, valorização dos recursos energéticos e proteção do meio ambiente). Com relação aos recursos hídricos, devem ser lembradas: a Lei n. 9.427/96, que cuida da energia elétrica (instituição da Agência Nacional da Energia Elétrica); a Lei n. 9.433/97, que instituiu a Política Nacional de Recursos Hídricos; e a Lei n. 9.984/2000, a qual criou a Agência Nacional de Águas. O que se quer mostrar com todos esses destaques é que a legislação brasileira está em harmonia com os interesses ambientais, uma vez que se nota o disciplinamento do interesse ambiental estabelecido pela Constituição Federal em várias leis ordinárias brasileiras.

Embora ainda existam algumas interpretações dissonantes, aqui se acata o entendimento de Fiorillo e Ferreira (2009, p. 35-45) no sentido de que a natureza jurídica do meio ambiente, é difusa (indivisível), não é um bem público e muito menos privado; é um bem de uso comum do povo, essencial à sadia qualidade de vida. Lembra Rosembuj (1995, p. 53) que a moderna jurisprudência dos Estados Unidos, a partir da Teoria de Coisa Comum do Direito Romano, entende que o interesse ou expectativa do 
ambiente é próprio da cidadania: a Administração é mera fiduciária e não proprietária do bem ambiental, predisposta para sua defesa e conservação. Pode-se dizer, entretanto, que o ordenamento tributário brasileiro não compagina os ideais ambientais determinados pela própria Constituição Brasileira nos dispositivos já destacados. A aduzida harmonia legislativa não pode ser verificada no próprio ordenamento constitucional tributário, uma vez que não são encontradas normas tributárias que procurem atender ao ditame constitucional de proteção ao meio ambiente. Ao serem observados os artigos 145 a 162 da Constituição Federal, pode-se verificar que não existem dispositivos constitucionais tributários relativos à proteção ambiental (Capítulo I: do Sistema Tributário Nacional). Podem ${ }^{4}$ ser citados os artigos $153, \S 3^{\circ}$, I e $\S 4^{\circ}$, I; artigo $155, \S 2^{\circ}$, III e $\S 6^{\circ}$, II como normas extrafiscais, mas que são incipientes sob o ponto de vista ambiental e deixam a critério do legislador infraconstitucional o regramento da proteção do equilíbrio ecológico.

E qual a necessidade em se inserir elementos tributários extrafiscais na Constituição e não deixar a critério da legislação infraconstitucional a preocupação ambiental? Ocorre que o Imposto sobre operações relativas à circulação de mercadorias e serviços (ICMS), como será visto, é o principal imposto nacional sobre o consumo e, basicamente, por intermédio dele se dá a tributação da energia, embora existam outros tributos como a Contribuição de Intervenção no Domínio Econômico (CIDE) e o Imposto de Importação (II) e de Exportação (IE), ambos de cunho federal, conforme estabelece o artigo 153, $\S 3^{\circ}$ da Constituição Federal, além das taxas. Esse imposto, o ICMS, é de competência estadual e seu trato é efetuado

4 Existe a Proposta de Emenda Constitucional (PEC) n. 353/2009, cuja parte de sua justificativa é interessante e instigante destacar aqui: "Na doutrina jurídica brasileira, o tema também tem sido negligenciado, talvez não por motivação político-ideológica, senão por desconhecimento. Essa ausência de percepção do problema, que também pode ser explicada pelo distanciamento da dogmática jurídica em relação a outros ramos das ciências sociais e econômicas, seria capaz de gerar, inclusive, defesas apaixonadas da inconstitucionalidade de proposições legislativas que almejassem introduzir o elemento ambiental em qualquer das normas de incidência de nosso sistema tributário nacional. Tal é a incipiência no Brasil sobre a RTA [Reforma Tributária Ambiental] que a PEC 233/2008, que trata da Reforma Tributária, sequer tangenciou a extrafiscalidade ambiental nos tributos modificados ou propostos”. (BRASIL, 1988, art. 149-161) 
de forma heterogênea entre os Estados Brasileiros, mesmo tendo-se em conta eventual tentativa de uniformização mediante Lei Complementar. O que se observa na prática legislativa tributária brasileira é uma disparidade entre os Estados. Há uma diferença muito grande, por exemplo, na tributação da própria energia com alíquotas diferenciadas, figuras complexas como a substituição tributária, peculiaridades regionais em espaços geográficos diferentes, que podem gerar distorções caso se visualize um quadro nacional harmonioso de interesse ambiental. Daí, portanto, a necessidade do exame constitucional, embora se saiba que a energia é tema que toca não apena o ICMS, mas praticamente todos os impostos.

E de que maneira poderia se dar a alteração constitucional tributária com vistas à proteção ambiental? Pela previsão e determinação constitucional tributária em se gravar pesadamente as condutas mais agressivas ao ambiente e pela desoneração das menos agressivas. No caso da energia, poderiam ser diferenciadas hipóteses de incidências tributárias entre combustíveis fósseis e biocombustíveis; promover atividades empresariais que tenham como resultado a menor emissão de gases poluentes, como o gás carbônico $\left(\mathrm{CO}_{2}\right)$; deveriam ser levados em conta os produtos com melhor rendimento energético na aquisição de mercadorias; a utilização de produtos potencialmente menos tóxicos deveriam possui carga tributária menor em relação aos mais tóxicos em toda a cadeia de extração, distribuição, comercialização e consumo. Enfim uma enorme gama de alternativas que deveriam ser previstas na Constituição visando à implementação infraconstitucional. Mas claro que todas estas hipóteses devem ter vinculação com os danos ambientais ou "externalidades" mensuráveis no processo. Oportunas as palavras de Benjamin (2007, p. 74):

Diante do novo quadro constitucional, a regulação estatal do ambiente dispensa justificação legitimadora, baseada em técnicas interpretativas de preceitos tomados por empréstimo, pois se dá em nome e causa próprios. Em face da exploração dos recursos naturais, a ausência do Poder Público, por ser a exceção, é que demanda cabal justificativa, sob pena de violação do dever inafastável de (prontamente) agir e tutelar. 
Nesse passo, então, as agressões ao meio ambiente devem ser limitadas ou evitadas e o poder público deve adotar mecanismos que venham a indicar condutas tendentes a mitigar tais danos ambientais. $\mathrm{Ci}$ tadas agressões ambientais são traduzidas na linguagem de Pigou ${ }^{5}$ como "externalidades" as quais são geradas por determinadas atividades econômicas cujos resultados negativos são suportados por toda a coletividade e não apenas por aqueles que os geraram ou deles se beneficiaram de alguma maneira. Em sentido reverso, deveria existir a "internalização" de tais custos sociais e ambientais, pois os custos de mercado não refletem os custo sociais do uso do recurso natural prejudicado.

Atualmente alguns sistemas tributários nacionais contam com mecanismos extrafiscais ambientais que podem cumprir um papel extremamente importante ao induzirem condutas positivas ou inibirem condutas negativas, modulando a respectiva carga tributária envolvida nas atividades econômicas. Nesse contexto é importante lembrar a Diretiva n. 2003/96 do Conselho da União Europeia:

(7) Como parte signatária da Convenção-Quadro das Nações Unidas sobre as Alterações Climáticas, a Comunidade ratificou o Protocolo de Quioto; a tributação dos produtos energéticos e, sendo o caso, da electricidade constitui um dos instrumentos disponíveis para a consecução dos objectivos do Protocolo de Quioto.

Como lembra a Organização para a Cooperação e Desenvolvimento Econômico $(\mathrm{OCDE})^{6}$, entidade que congrega e reúne as experiências de grande parte da economia mundial, os governos possuem diversos instrumentos que visam a proteção ambiental:

instrumentos de mercado (tributos ambientais [examinados aqui]) ou certificados de emissão que funcionam em um sistema de comércio de emissões, em leilões ou distribuídos gratuitamente. Estes licenças e créditos podem ser negociados normalmente e depositados em períodos de tempo e têm características e efeitos semelhantes aos impostos.

Foi Pigou quem começou a desenvolver a teoria da externalidade em sua obra Economics of Welfare (1920). Em versão espanhola, La Economía del bienestar (1946).

6 Taxation, Innovation and the Environment. (OCDE, 2010, p. 22) 
a) mecanismo de regulação ou chamados de "comando e controle". São os mecanismos que visam impor limites administrativos às atividades empresariais. Envolvem limites de emissão, portarias de tecnologia, etc. São normalmente dirigidas a indústrias individuais ou a produtos específicos com o foco, geralmente, em grandes operadores. Adotados amplamente no Brasil; b) acordos de adesão voluntária; c) subsídios e informações.

Mas essa entidade, a OCDE (2010, p. 154), após efetuar um longo estudo de casos teóricos e práticos, concluiu que nas abordagens dos países para a política ambiental, os tributos (OCDE, 2010, p. 136-138) por si só não são capazes de tratar adequadamente todos as questões ambientais, nem de superar sozinhos os desafios para a sua implementação, mas devem ter um papel central na abordagem da política ambiental.

Sugere-se ao estudioso do tema que inicie, ou, no mínimo complemente, seu raciocínio com base nestes dados antes de lançar dúvidas ou pessimismos em relação a uma reforma tributária ambiental brasileira, principalmente quando começa a atacar citada ideia com argumentos fundados em mero aumento de arrecadação disfarçado de tributação ambiental. Há que se fazer uma análise científica do tema, notadamente quando envolve elementos de outras searas do conhecimento humano, como é o caso dos resultados voltados às questões econômicas, sociais e ambientais. O mero contraste de opiniões jurídico-doutrinárias ou mesmo econômicas isoladas, sem contexto, passam a representar pouco frente às experiências e dados catalogados em outras nações e sistemas tributários. É forçoso afirmar, portanto, que o sistema tributário brasileiro não se volta a questões ambientais, em contraste com legislações de alguns países que já incorporaram temas ambientais buscando a chamada economia inteligente o que em linhas posteriores será visto.

\subsection{Informações sobre a Utilização da Energia no Brasil e no Mundo}

Como destaca Leite (2007, p. 48), no início do século XIX, o Brasil tinha população diminuta quando comparada a sua dimensão geográfica e à grandeza de suas florestas. A extensa colônia de Portugal entrava no século XIX como uma sociedade da lenha e escravos (portos fechados 
e proibição de atividades manufatureiras pela Coroa). O desbravamento de áreas para a agricultura e a pecuária na ocupação progressiva e continuada do território assegurou, por muito mais de um século, suprimento abundante de lenha como recurso energético dominante, para a produção e para uso residencial (cozimento e aquecimento de água). Até 1915, o recurso energético mais importante foi a lenha. Entre 1915 a 1941 houve um crescimento na utilização do carvão mineral, derivados de petróleo e hidreletricidade e a lenha começa a perder espaço. Em meados do século $\mathrm{XX}$, a situação do impressionante domínio da lenha inspirava uma crescente preocupação com o desmatamento indiscriminado. Isso provocou a elaboração de um código florestal (Decreto n. 23.793/1934) quase simultaneamente com os de minas e de águas. Tal Código tratou da preservação de maciços florestais, das florestas remanescentes, das artificiais, das de conservação perene e rendimento, e das que integravam parques nacionais. (LEITE, 2007, p. 90)

Para fim de comparação, podem ser apresentadas algumas informações obtidas a partir de um quadro do consumo de energia no Brasil de 1941 fornecido por Leite (2009, p. 90). No referido ano e conforme tal quadro, o consumo de energia no Brasil foi de 18,36 toneladas equivalentes de petróleo - tep e o consumo estava concentrado no uso da lenha (73\% do total). Setenta anos depois, em 2011 e segundo Relatório do Ministério das Minas e Energia (BRASIL, 2011), o consumo total de energia passou a ser de 247 tep, com 44\% do total, sendo utilizada energia renovável. Ou seja, o consumo brasileiro aumentou 13 vezes neste período.

Pode-se afirmar, ademais, que o Brasil possui uma situação mais confortável em relação ao resto do mundo quanto ao uso de energias não renováveis. Segundo este último relatório citado, depende em torno de $56 \%$ de energia não renovável, enquanto os países da OCDE (países em sua maioria chamados de industrializados) dependem em torno de $92 \%$ de energia não renovável (petróleo, urânio, gás natural, etc.) (BRASIL, 2011, p. 16). Na página 19 do citado periódico há uma observação muito interessante. Segundo interpretação dos dados deste relatório, o consumo industrial de energia dos países da OCDE, no período de 1973 a 2009, recuou de 958 milhões tep para 773 milhões tep, apesar do consumo final total de energia ter aumentado de 3.076 milhões tep para 3.886 milhões 
tep. Segunda ainda a Revista, trata-se de um indicador que mostra que os países ricos, além da inovação tecnológica, vêm transferindo aos países em desenvolvimento grande parte da indústria "pesada" - intensiva em energia e capital. Entende-se no presente estudo que isto significa maior poluição gerada pela energia.

Efetuando-se um rápido exame nas informações acima, pode-se concluir que o Brasil está em uma situação um pouco mais confortável caso se considere o consumo e as fontes disponíveis de energias renováveis em relação às não renováveis. Mas não se pode afirmar, em razão desta posição brasileira favorável (comparativamente), que a mesma seja a mais adequada do ponto de vista tributário, tendo-se em conta suas necessidades e prioridades sociais. Não se pode asseverar, também, que as fontes disponíveis de energia do resto do mundo apontem para um futuro tranquilo, principalmente, no caso dos países membros da OCDE. Assim sendo, os países membros da OCDE são extremamente dependentes das fontes não renováveis de energia, dos derivados de petróleo, embora de modo decrescente. Também vale ressaltar que mais de $10 \%$ da energia disponível para os países membros da OCDE provém de fonte nuclear. Tal fato merece destaque levando-se em conta, principalmente, a segurança da população, como nos desastres recentes de Fukushima no Japão (ou então mais antigos como Chernobil - Ucrânia em 1986), e os impactos ambientais, em virtude dos detritos tóxicos resultantes da utilização deste tipo de energia.

Depois do acidente de Fukushima, a Alemanha implantou um tributo sobre a energia nuclear. Tal imposto faz parte do chamado programa "Energiewende" ("troca de energia" em tradução livre) orientado a abandonar por completo a energia nuclear até o ano de 2050. (ADOLF, 2013, p. 87)

Há que se ter em mente, para a discussão da adequada tributação da energia, a quantidade de emissão de $\mathrm{CO}_{2}$ (gás carbônico), prejudicial ao meio ambiente, produzido pelo perfil de consumo dos países envolvidos.

Na referida Resenha Energética Brasileira, no item 3.2, p. 7, consta que: 
No país [Brasil], a emissão de 2011 pelo uso de energia ficou em 1,43 tonelada de $\mathrm{CO}_{2}$ por tep da OIE [oferta interna de energia] enquanto que nos países da OECD esse indicador ficou em 2,33 $\mathrm{tCO}_{2}$ /tep [toneladas equivalentes de petróleo] de OIE (2009), e no mundo ficou em 2,4 $\mathrm{tCO}_{2}$ /tep de OIE (2009).

A China e os Estados Unidos, com 12.140 milhões t de emissões de $\mathrm{CO}_{2}$, responderam por $41 \%$ das emissões mundiais de 2009 , no montante de 29.380 milhões t $\mathrm{CO}_{2}$. (BRASIL, 2011, item 3.2)

Pode-se agora, comparar estes dados com as antigas Constituições Brasileiras, e, posteriormente, com a atual Constituição.

\subsection{Constituições Brasileiras - de 1940 até 1988 e a Tributação da Energia}

Observa-se a seguir o tratamento que foi dado à tributação da energia pelas constituições brasileiras anteriores a de 1988 e tal como esta última, pode-se constatar que não existiam preocupações ambientais.

a) a Lei Constitucional n. 4, de 4 de setembro de 1940 - Emenda o artigo 20 da Constituição dos Estados Unidos do Brasil de 10 de novembro de 1937 não fazia menção à tributação expressa da energia elétrica, uma vez que a lenha ainda representava grande parte da matriz energética no Brasil;

b) a Constituição dos Estados Unidos do Brasil de 18 de setembro de 1946 (artigo 15, III e $\S 2^{\circ}$ ) ampliou a tributação para alcançar a energia elétrica e ainda como imposto único;

c) a Constituição da República Federativa de 1967 (artigo 22, VIII, IX e X) alargou a base da tributação da energia no Brasil;

d) a Emenda Constitucional n. 1 de 17 de Outubro de 1969 da Constituição da República Federativa de 1967 (artigo 21, VIII e IX) demarcou a tributação no Brasil, impedindo-se claramente a criação de outros tributos sobre a energia. 


\section{Quadro Constitucional Atual}

Com Loureiro $(2009$, p. 37), pode-se afirmar que a Constituição Brasileira de 1988 estruturou todo o trato da matéria "energia" em dois temas jurídicos relacionados, mas conceitualmente distintos: "fontes" e "atividades"; uma disciplina das fontes de energia e uma disciplina das atividades energéticas. No primeiro caso, trata de objetos ou bens jurídicos; no segundo, tarefas ou competências materiais. Essa divisão (fontes, atividades) delimita o espaço público e o privado e estabelece a divisão de competências estatais (normativa, de fiscalização, de tutela, etc.).

De fato, a preocupação preponderante da Constituição é com as fontes finitas de energia. Sobre o petróleo, a Constituição Federal considerou-o como jazida, bem público federal (artigo 20, V e IX); as atividades a eles relacionadas foram reservadas ao Estado (artigo 177, I a IV). Sobre o gás natural, cabe destacar os artigo $25, \S 2^{\circ}$ (exploração direta pelo Estado ou por concessão) e artigo 177, I (monopólio da União, a pesquisa e a lavra de suas jazidas). A água, relativa à energia hidrelétrica, foi tratada pela Constituição nos artigo 21, XII, "b" (exploração, diretamente ou mediante autorização, concessão ou permissão dos serviços e instalações de energia elétrica) e XIX (instituição de sistema nacional de gerenciamento de recursos hídricos e definir critérios de outorga de direitos de seu uso); e artigo 23, XI (competência comum da União, dos Estados, do Distrito Federal e dos Municípios registrar, acompanhar e fiscalizar as concessões de direitos de pesquisa e exploração de recursos hídricos e minerais em seus territórios).

Quanto às fontes nucleares, deve-se mencionar os artigo 21, XXIII (competência da União em explorar os serviços e instalações nucleares) e artigo 177, V (monopólio da União a relativamente às atividades ligadas a minérios e minerais nucleares e seus derivados, com exceção dos radioisótopos), além do artigo 49, XIV (competência exclusiva do Congresso Nacional aprovar iniciativas do Poder Executivo referentes a atividades nucleares) e artigo $225, \S 6^{\circ}$ (as usinas que operem com reator nuclear deverão ter sua localização definida em lei federal, sem o que não poderão ser instaladas). Antes de extrema importância, o carvão não obteve menção específica constitucional em seu trato. As menções à energia e 
matéria-prima renováveis previstas na Constituição Brasileira podem ser encontradas no artigo 176, $\S 4^{\circ}$ e artigo 238. Com efeito, em todos os dispositivos destacados, nota-se grande preocupação com a energia de fontes não renováveis em comparação com as renováveis. Também é grande a distinção que se faz entre as fontes e atividades energéticas, o que define o trato constitucional da energia no Brasil.

Volte-se, contudo, ao exame da disciplina tributária da energia.

$\mathrm{O}$ art. $155, \S 3^{\circ}$, da Constituição Federal estabelece:

Art. 153 Compete à União instituir impostos sobre:

I - importação de produtos estrangeiros;

II - exportação, para o exterior, de produtos nacionais ou nacionalizados;

$[\ldots]$

Art. 155 Compete aos Estados e ao Distrito Federal instituir impostos sobre:

$[\ldots]$

II - operações relativas à circulação de mercadorias e sobre prestações de serviços de transporte interestadual e intermunicipal e de comunicação, ainda que as operações e as prestações se iniciem no exterior;

$[\ldots]$

$\S 3^{\circ}$ À exceção dos impostos de que tratam o inciso II do caput deste artigo e o art. 153, I e II, nenhum outro imposto poderá incidir sobre operações relativas a energia elétrica, serviços de telecomunicações, derivados de petróleo, combustíveis e minerais do País.

Cabe mencionar ainda o artigo 149-A da Constituição Federal:

Art. 149 A Os Municípios e o Distrito Federal poderão instituir contribuição, na forma das respectivas leis, para o custeio do serviço de iluminação pública, observado o disposto no art. 150, I e III.

Parágrafo único. É facultada a cobrança da contribuição a que se refere o caput, na fatura de consumo de energia elétrica. 
Estes são os dispositivos mais importantes em matéria tributária os quais ensejam análise.

a) Tributos federais

- Imposto de Importação (II)

Previsto no artigo 153, I, da Constituição Federal de 1988, cuja hipótese de incidência consta no artigo 19 do Código Tributário Nacional (CTN), e de caráter extrafiscal (em sentido amplo), o presente imposto cumpre função de proteção da indústria ou dos interesses nacionais econômicos, mas não propriamente ambientais. O Imposto de Importação é disciplinado pelo Decreto-Lei n. 37 de 18 de novembro de 1966;

- Imposto de Exportação (IE)

Também de cunho extrafiscal (sentido amplo), mas sem uma preocupação ambiental, o presente imposto está previsto no artigo 153, II, da Constituição Federal, cuja hipótese de incidência consta no artigo 23 do CTN. Note-se que não só os produtos nacionais, mas também os nacionalizados são passíveis de tributação pelo imposto. O Imposto de Exportação é disciplinado pelo Decreto-Lei n. 1.578, de 11 de outubro de 1977.

- Contribuição de Intervenção no Domínio Econômico (CIDE Combustíveis)

Conforme destacado do $\S 3^{\circ}$, artigo 155: "nenhum outro imposto poderá incidir sobre operações relativas a energia elétrica, serviços de telecomunicações, derivados de petróleo, combustíveis e minerais do País". (grifo nosso)

Por se tratar de contribuição e não de um imposto, a União pôde instituir a chamada CIDE - Combustíveis, pela Lei n. 10.336, de 19 de dezembro de 2001, a qual poderá incidir sobre determinados combustíveis conforme estabelece o artigo $3^{\circ}$ da referida lei.

Interessante destacar que o $\S 1^{\circ}$ do artigo $1^{\circ}$ da mencionada lei determina a destinação da referida contribuição: pagamento de subsídios a preços ou transporte de álcool combustível, de gás natural e seus derivados e de derivados de petróleo, financiamento de projetos ambientais relacionados com a indústria do petróleo e do gás e de programas de infraestrutura de transportes. Apreciando-se tais dispositivos, não se pode 
afirmar que referido tributo seja dotado de extrafiscalidade ambiental em sentido estrito, pois suas hipóteses de incidência não induzem a adotar condutas benéficas ao meio ambiente. Apenas o destino dos recursos é voltado ao financiamento de projetos ambientais. Entende-se neste trabalho que a vinculação da arrecadação tributária não matiza como ambiental um determinado tributo. É importante que se diga que o tributo ambiental não se destina a ter arrecadação zero; mas também não se fundamenta em capacidade arrecadadora para sua legitimação. A finalidade da tributação extrafiscal ambiental é a proteção do equilíbrio ecológico ou do meio ambiente. A finalidade dos tributos fiscais, grosso modo, é o suprimento dos gastos públicos. A $\mathrm{OCDE}^{7}$ lembra que a fiscalidade ambiental está relacionada a qualquer imposto cuja hipótese de incidência se considere de especial relevância para o meio ambiente. Ademais, a OCDE (2010, p. $142)^{8}$ ainda sugere (no Guia da tributação ambiental e políticas de mercado), que a arrecadação dos tributos ambientais (citando dentre várias razões, como tendência decrescente de arrecadação, baixo percentual de arrecadação em relação ao total de impostos arrecadados) não seja vinculada e seja destinada a um fundo comum de arrecadação.

Nesse sentido, a chamada CIDE destoa de um sistema tributário eminentemente extrafiscal ambiental.

- Imposto sobre produtos industrializados (IPI)

O IPI recebeu previsão constitucional pelo artigo 153, IV e possui Regulamento dado pelo Decreto n. 7.212/2010.

Claro, que, em razão do que dispõe o artigo $155, \S 6^{\circ}$ da CF/88, o referido imposto não incide sobre operações relativas a energia elétrica, derivados de petróleo e combustíveis.

Ocorre, contudo, que se trata de um tributo extrafiscal, voltado à indústria brasileira, possuindo uma nota de seletividade em razão do que dispõe o artigo 153, $\S 3^{\circ}$, III, da Constituição Federal, pois, suas alíquotas deverão ser diferenciadas em função da essencialidade dos produtos a

7 Disponível em: <http://www2.oecd.org/ecoinst/queries/taxinfo.htm>. Acesso em 29 mar. 2013.

8 Taxation, Innovation and the Environment. (OCDE, 2010, p. 142) 
qual poderia ser aplicada em todos os produtos. Resta saber se tal essencialidade poderia permitir a tributação de forma diferenciada, por exemplo, para máquinas ou veículos menos poluentes, ou que consumam menos energia ou ainda que dependam de energia renovável, mas de maneira ampla e não pontual como se observa na Tabela do Imposto (TIPI) a qual define suas alíquotas.

b) Tributos Estaduais

- Imposto sobre operações relativas à circulação de mercadorias e serviços (ICMS) ${ }^{9}$

Principal tributo estadual, o ICMS possui previsão constitucional no artigo 155 , II.

Como informação e utilizando-se a Lei Orgânica do ICMS do Paraná, Lei n. 11.580/96, tem-se que as alíquotas internas são de 12\% para combustíveis de aviação, óleo diesel; 28\% para gasolina; 29\% para energia elétrica e $18 \%$ para o álcool etílico.

Não se pode esquecer o inciso III, do $\S 2^{\circ}$ do artigo 155 da Constituição Federal que menciona a aplicação da seletividade no disciplinamento do presente tributo estadual. É inegável a essencialidade da energia em todos os aspectos da vida social e não apenas para as atividades empresariais ou econômicas. Daí a importância do tema vinculado ao ICMS. O problema é que a essencialidade não envolve necessariamente a proteção ambiental. Um determinado bem pode ser essencial, mas isto não significa dizer que foi obtido com base em preocupações ambientais. Parte-se do princípio que toda a energia é essencial para as atividades produtivas, sociais, para o conforto e mesmo ao lazer. Mas deve-se saber, reconhecida sua essencialidade, se há distinção no trato das diversas espécies de energia com respeito às preocupações ecológicas.

E por envolver grandes recursos financeiros, impactos ambientais, dentre outros temas, a tributação do petróleo pelo ICMS provoca discussões judiciais importantes. Prova disso é a Ação Direta de Inconstitucionalidade (ADI) n. 3.019 (BRASIL, 2003), ainda não julgada em

9 Vários são os temas abordados envolvendo a tributação da energia elétrica, de modo específico, em Borges e Leme (2010). 
definitivo, pela qual a Procuradoria Geral da República questiona a constitucionalidade da Lei n. 4.117/2003 do Estado do Rio de Janeiro. Mencionada lei instituiu a incidência ICMS sobre as operações de petróleo. A discussão ${ }^{10}$ se abre justamente no momento em que se considera que a incidência do ICMS ocorreria somente no instante que o petróleo se torna mercadoria. E se este instante dar-se-ia apenas no momento posterior à sua extração. Questão importante a ser analisada é saber se o petróleo, sendo energia em estado bruto, poderia ser considerado mercadoria e assim já ser tributado como tal.

É de se lembrar de que a energia, para fins de incidência do ICMS deve ser considerada como mercadoria, conforme entendimento exarado no Recurso Especial n. 222.810/MG (BRASIL, 2000);

- Imposto sobre a propriedade de veículos automotores (IPVA)

Naturalmente o IPVA não ${ }^{11}$ incide sobre as fontes de energia. Mas existem dispositivos nas leis estaduais do citado imposto que desoneram veículos que utilizam determinados combustíveis como o Gás Natural Veicular (GNV). Como exemplo pode ser citada a alínea "c", do inciso I, do artigo $4^{\circ}$ da Lei do IPVA paranaense - Lei n. 14.260/2003.

Deve ser questionado se veículos mais novos ou econômicos não deveriam ter uma tributação menor uma vez que poluem menos em razão de trafegarem com motores supostamente mais modernos dotados de combustíveis renováveis como o álcool.

Leicester (2013, p. 45) noticia que no Reino Unido, desde 2001, existe um imposto anual sobre a propriedade de veículos (Vehicle exci-

\footnotetext{
10 Esta discussão pode ser encontrada em Silva (2005, p. 116-123); bem como em Bechara e Varella (2005, p. 301 a 321).

11 Outros tributos poderiam contar com incidências fiscais diferenciadas levando-se em conta a utilização da energia, embora suas previsões legislativas não tenham relação direta com a mesma. Por exemplo, a tributação do Imposto sobre a propriedade predial e territorial urbana (IPTU), imposto municipal, poderia conter benefícios fiscais, alíquotas diferenciadas para as unidades de habitação que contassem com energia renovável, como a eólica, ou que tivessem equipamentos de monitoramento para conservação da energia. Enfim aparentemente são poucos os tributos que incidem diretamente sobre a energia, mas ela está presente em todas as atividades econômicas e sociais.
} 
se duty - VED) o qual grava sua incidência na medida da eficiência do consumo de combustível (emissões de dióxido de carbono por quilômetro rodado). Nos Estados Unidos há o chamado Gas Guzzler Tax, de 1978, (Imposto sobre veículos com grande consumo de gasolina) que é um imposto especial sobre a venda de veículos com eficiências de combustível inferiores ao nível legal. (SALABERT; PÉREZ; CANO, 2008, p. 1.024)

c) Taxas

Conforme determina a Constituição Federal, artigo 145, II, a União, os Estados, o Distrito Federal e os Municípios poderão instituir taxas.

E como determina o artigo 77 do Código Tributário Nacional:

As taxas cobradas pela União, pelos Estados, pelo Distrito Federal ou pelos Municípios, no âmbito de suas respectivas atribuições, têm como fato gerador o exercício regular do poder de polícia, ou a utilização, efetiva ou potencial, de serviço público específico e divisível, prestado ao contribuinte ou posto à sua disposição.

Segundo alguns autores as taxas se prestam perfeitamente à tarefa de proteção ambiental em razão da atividade de fiscalização e pela prestação obrigatória de serviços que tenham caráter ambiental (FERRAZ, 2005 , p. 351). Ribas (2005, p. 699) entende que as taxas se configuram num instrumento de aplicação próxima, imediata e fácil ao alcance das finalidades ecológicas, podendo ser usadas: a) sobre poluição de água, para diminuição de ruídos, etc.; b) para cobrir custos de construção de centrais de tratamento de resíduos e c) administrativamente ligadas à autorização ${ }^{12}$ e controle da produção e comercialização de produtos autorizados, como compostos químicos e inspeção de veículos.

d) Contribuições de melhoria

Prevista pelo artigo 145, III, da Constituição Brasileira de 1988, e no artigo 81 do Código Tributário Nacional, a contribuição de melhoria poderá ser cobrada pela União, pelos Estados, pelo Distrito Federal ou pelos Municípios, no âmbito de suas respectivas atribuições, e poderá ser

12 Sobre as autorizações e licenças ambientais como instrumentos de controle ambiental cabe destacar Silva (2010, p. 280-288). 
instituída para fazer face ao custo de obras públicas de que decorra valorização imobiliária, tendo como limite total a despesa realizada e como limite individual o acréscimo de valor que da obra resultar para cada imóvel beneficiado.

Considera Ferraz (2005, p. 351) que a contribuição de melhoria no âmbito ecológico levaria a uma equação muita justa na criação de parques e áreas de preservação ambiental.

Interessante destacar que a doutrina espanhola, tratando a contribuição de melhoria como contribuição especial ${ }^{13}$, chega a admitir a chamada contribuição especial ("de melhoria", para o caso brasileiro) negativa. Por exemplo, tal contribuição negativa gravaria uma atividade danosa (produção de resíduos) autorizada pela administração que prejudica um grupo de pessoas por determinadas empresas. Em lugar de um benefício especial, se produz um prejuízo especial. Daí falar em contribuição negativa, porque os que vão contribuir não serão beneficiados diretamente.

Herrera Molina (2000, p. 107), sugerindo uma denominação melhor como "contribuições negativas por gastos especiais", explica que se trata de uma figura paralela às taxas, mas com a diferença que a obra pública não significaria um benefício direto aos contribuintes, dando como outro exemplo a contribuição exigida às companhias aéreas que utilizam aeroportos, destinada a financiar medidas de isolamento acústico nas casas próximas.

No caso da energia e da contribuição de melhoria, estes exemplos podem ser interessantes com respeito à construção e melhoria de subestações, torres de energia, usinas, enfim um elenco grande de situações que devem ser pontualmente examinadas.

\footnotetext{
13 Ley 58/2003, Ley General Tributaria, artigo 2", 2, "b": Contribuciones especiales son los tributos cuyo hecho imponible consiste en la obtención por el obligado tributario de un beneficio o de un aumento de valor de sus bienes como consecuencia de la realización de obras públicas o del establecimiento o ampliación de servicios públicos.
} 


\section{A Tributação Ambiental e a Energia - Necessidade de um Novo Marco Constitucional}

Toda a exposição efetuada neste estudo até agora foi feita para mostrar a inafastável relação entre normas constitucionais ambientais, a energia e sua tributação. Porém, pode-se constatar que a atual Constituição Brasileira não determina, por meio de seus dispositivos, a vinculação do tema tributário à proteção ambiental, deixando à mercê do legislador infraconstitucional a tutela do bem ambiental.

Ocorre que a tributação ambiental, em razão de sua componente extrafiscal, pela indução de condutas, pode promover a proteção do meio ambiente, gravando de forma mais rigorosa as atividades que degradem o meio ambiente e, em contrapartida, esta mesma tributação pode desonerar ou incentivar condutas que visem à proteção ecológica. A energia, neste aspecto, tem papel fundamental, pois está presente em praticamente todas as atividades da vida social e representa grande parte da arrecadação ${ }^{14}$ dos tributos ambientais.

Chama-se a atenção para este fato porque diversos países ${ }^{15}$ já reformularam seus sistemas nacionais tributários com a intenção de contar com mecanismos fiscais para proteção ambiental com resultados expressivos.

Gago Rodríguez e Labandeira Villot (2013, p. 172) informam que já se pode dizer que existem três gerações de Reformas Fiscais Verdes iniciadas a partir de 1990:

- Primeira Geração: Suécia (1991); Noruega (1992) e Holanda (1992). Estes países introduziram impostos ambientais e reduções compensatórias em seus impostos de renda e sociedades em um esquema de neutralidade de arrecadação;

\footnotetext{
14 Os tributos sobre a energia na Europa representam quase 75\% de toda arrecadação tributária ambiental. Disponível em: <http://appsso.eurostat.ec.europa.eu/nui/show. do?dataset=env_ac_tax\&lang=en $>$. Acesso em: 29 de março de 2013.

15 No âmbito do Direito Comunitário Europeu e sobre o tema da tributação da energia (abordado historicamente até 2001), bastante importante o artigo de Rozas Valdés (2001).
} 
- Segunda Geração: Reino Unido (1996), Finlândia (1998), Alemanha (1999), Estônia (2006) e República Tcheca (2008). Esses países introduziram impostos ambientais e reduções compensatórias em contribuições sociais, também em um esquema de neutralidade de arrecadação; e

- Terceira Geração: Suíça (2008), Irlanda (2010), Austrália (2011) e Itália (2012). Esses países introduziram impostos ambientais e compensações com políticas mistas de reaproveitamento de ingressos aplicados a consolidação fiscal, câmbio climático, eficiência energética, energias renováveis e investigação, desenvolvimento e inovação.

Pela análise da doutrina nacional e dos meios de informação, de fato, há que se constatar que existe uma grande preocupação que uma reformulação do sistema tributário nacional, com a inserção de novos elementos de cunho ambiental, sirva apenas como justificativa para a arrecadação de mais impostos. As experiências internacionais, entretanto, poderiam moldar o caso brasileiro, pois tais experiências apontam para o fato de que as reformas tributárias verdes não significam necessário aumento de arrecadação global em relação ao que se produz economicamente no país. Normalmente tais reformas vêm acompanhadas de desonerações entre outros setores, como o setor laboral, de renda ou outros impostos das empresas, visando uma neutralidade da arrecadação.

O caso da reforma alemã de 1999 é peculiar, pois elencou quatro possíveis efeitos dos impostos ambientais:

a) o primeiro efeito consiste em gravar de forma mais pesada os bens ou atividades que no contexto alemão vem a significar "grava o que queimas, não o que ganhas", e tem como consequência o; b) segundo efeito, o objetivo de estabilizar o sistema de seguridade social e reduzir de forma significativa os custos trabalhistas; c) o terceiro efeito é a criação de emprego e da ecoinovação que podem ser resultado deste processo e por último e o d) o quarto efeito que redundará em uma série de benefícios para o meio ambiente, como a redução de emissão de gás carbônico, por exemplo. No quadro de uma reforma tributária ambiental 
procura-se o chamado duplo dividendo que significaria os resultados positivos ambientais com o ganho ou equilíbrio financeiro.

O caso alemão novamente dever ser citado. Ocorreu a criação de 250.000 novos empregos no setor da chamada economia ecológica de 1999, relacionados à energia renovável. Entre 1999 a 2010, as emissões de gás carbônico na Alemanha foram reduzidas a 3\%, embora o crescimento econômico tenha sido ligeiramente positivo. Segundo Adolf (2013, p. 85) o pacote alemão de medidas fiscais contribuiu para superar a crise econômica de 2000-2005 e é um exemplo de êxito ${ }^{16}$ de reforma tributária ambiental. Cabe ressalvar, contudo, que as medidas fiscais devem ser analisadas levando-se em conta as peculiaridades de cada país. Os resultados obtidos não são apenas relativos à proteção ambiental, mas possuem impactos no equilíbrio orçamentário, pela desoneração de outros setores produtivos ou do trabalho e também pelo aspecto de inovação empresarial que induz as empresas a investirem em pesquisa e desenvolvimento. A inovação tem pertinência com a chamada Hipótese de Porter ${ }^{17}$. As empresas, pela inovação, encontram menores níveis de poluição em suas atividades. Em razão disso, passam a ter maior rentabilidade empresarial em setores antes não explorados economicamente.

Mas como, efetivamente, se pode estabelecer um novo marco constitucional visando a tributação ambiental dadas as experiências internacionais apropriadas ao caso brasileiro?

Entende-se, neste estudo, que não há qualquer empecilho de ordem formal para se reformular o sistema tributário com o desiderato da proteção ambiental. Não se pode aceitar que uma reforma tributária não possa incorporar um novo tributo ecológico do ponto de vista formal constitucional ou novos elementos para proteção ambiental nos tributos já existentes. Já se ressalvou que, em razão das chamadas cláusulas pétreas da Constituição, artigo $60, \S 4^{\circ}$, dados os direitos e garantias individuais, do

\footnotetext{
16 No mesmo sentido e sobre os resultados benéficos para a economia alemã, ver Görres (2006, p. 213). Destaca esse autor que a Alemanha passou a ser líder em tecnologia eólica e exportador de tecnologias eólicas e alternativas.

17 Taxation, Innovation and the Environment. Organização para a Cooperação e Desenvolvimento Econômico. (OCDE, 2010, p. 75)
} 
direito de propriedade e liberdade ${ }^{18}$, poderia haver limitação constitucional para a incorporação de um novo tributo ${ }^{19}$ ou para mudanças nos tributos já existentes. Deveria ser respondido se novas outorgas tributárias ou alterações constitucionais, no âmbito de uma reforma, poderiam ser efetuadas e dirigidas aos entes federativos de modo diferente do que hoje se estabelece, respeitada a forma federativa de Estado, a separação de poderes, as limitações ao poder de tributar (artigo 150-153 da Constituição Federal de 1988) e os direitos e garantias individuais. Resta saber se a estrutura tributária brasileira é imutável, dentro da normalidade institucional, para que se possa afirmar que não se aceita um novo tributo com fim ecológico ou novos elementos de proteção ambiental nos tributos já existentes. Optar por uma reforma tributária com a inserção de novos tributos ou (elementos de proteção ambiental nos já existentes), não significa afirmar que se tenha que manter os antigos; que a carga tributária tenha que aumentar afetando a propriedade, se é que assim pode ser pensado. Aliás, quanto maior a eficiência ${ }^{20}$ de tributo ecológico, menor será sua arrecadação ${ }^{21}$ e este fato não impede a desoneração de outros setores ou atividades econômicas. E claro, deverá existir um sopesar de princípios, mas há que se ter claro, como afirma Gallo (2011, p. 97), que “os direitos

\footnotetext{
18 Alerta Gutmann (2011, p. 3, tradução nossa) que: “Certos empreendedores, quando confrontados, consideram o tributo como uma forma de expropriação organizada pelo Estado, interferindo mesmo na liberdade do trabalho. Quer dizer, eles consideram o tributo como uma intervenção, mais ou menos legítima, do Estado no exercício dos direitos dos mais sagrados. Então, o princípio da imposição tributária deveria ser questionado? A resposta é evidentemente negativa. O tributo é o meio pelo qual o Estado atende às suas necessidades, ou seja, a todos os cidadãos. Ele também é utilizado para orientar a ação das empresas, quer seja para incitar a investir em um setor ou zona geográfica, ou para dissuadir a se envolver em certas atividades consideradas prejudiciais".

19 Ver, por exemplo, Costa (2005, p. 319-320).

20 “O Direito Ambiental tem aversão ao discurso vazio; é uma disciplina jurídica de resultado, que só se justifica pelo que alcança, concretamente, no quadro social das intervenções degradadoras". (BENJAMIN, 2007, p. 67)

21 Embora se saiba que “[...] o ingresso zero não é o resultado ideal de um tributo de ordenação ambiental, pois se trata de internalizar os custos reduzindo-se a contaminação de modo mais eficiente possível, e não de sufocar a atividade supostamente contaminante, o que exigiria medidas sancionadoras”. (HERRERA MOLINA, 2000, p. 176-177, tradução nossa).
} 
patrimoniais não constituem os únicos pressupostos da equidade do sistema fiscal".

Não se vislumbra, do mesmo modo, a infração ao artigo $3^{\circ}$ do Código Tributário Nacional: o tributo não deve ser utilizado como sanção de ato ilícito. Alguns estudiosos entendem que, pelo princípio de "quem contamina paga", o tributo estaria sendo usado como instrumento de sanção. A tributação ambiental deve ser dada no espaço da licitude e do tolerável. A questão é que alguns raciocinam que todo o ato de poluição seria ilícito e o pagamento do tributo poderia até mesmo legitimar tal ilicitude, ou ainda, como chegam a afirmar alguns, o poluidor, pelo pagamento do tributo, passaria a ter direito a poluir. $\mathrm{O}$ intuito de eventual concepção de norma tributária extrafiscal não seria a de cobrar pela contaminação, mas sim em estabelecer normas indutoras de comportamento em um âmbito solidário. Ademais, a tributação ambiental se legitima constitucionalmente pela proteção do meio ambiente e não apenas por seu aspecto arrecadador. Os maiores problemas para alterar o sistema constitucional tributário brasileiro, com vistas à proteção e equilíbrio ambiental, entendidos neste trabalho, não são questões de ordem formal constitucional, mas sim de vontade política. $\mathrm{A} \mathrm{OCDE}^{22}$ lembra que a decisão política para implementar tal alteração passa por dificuldades como falta de informações sólidas, custos de administração tributária, temas de competitividade setorial (e pode-se entender também como competitividade internacional). Mas entende, esta mesma entidade, que o sucesso de tal implementação passa pela observância de questões distributivas, competitividade empresarial, simplificação fiscal administrativa e pela confiança em se informar tal programa tributário a todos os envolvidos.

\section{Conclusão}

O tema da reforma tributária no Brasil deve envolver todos os agentes políticos, econômicos e acadêmicos.

Não se pode admitir que um tema tão relevante, porém, fique limitado à análise puramente teórica doutrinária; daí a inserção de expe-

22 Taxation, Innovation and the Environment. (OCDE, 2010, p. 143-146) 
riências internacionais destacadas neste texto. As necessidades estatais demandam recursos e esta é a finalidade principal de qualquer sistema tributário. Mas, modernamente, tais sistemas podem conter oportunas ferramentas que visam induzir condutas benéficas de proteção ecológica, pela chamada extrafiscalidade ambiental. E a energia, nesse contexto, pelo fato de estar presente em todas as atividades humanas; representar grande parte dos recursos ao Estado com sua tributação e ainda impactar na natureza de forma negativa, caso seja indevidamente utilizada, é tema central em qualquer debate. Pela análise constitucional e pelas experiências internacionais aqui expostas, chega-se a conclusão que além de oportuna, uma reforma tributária nacional com preocupação ambiental é necessária e urgente, não apenas pelo mero aspecto ambiental que a legitima, mas pelo chamado duplo dividendo; resultados financeiros e ambientais, além do caráter de inovação e de oportunidade empresarial relacionados a chamada hipótese de Porter no texto tratada. A tributação da energia neste quadro deve ser observada de maneira obrigatória.

\section{Referências}

ADOLF, Constance. De contrapartida financiera a oportunidad; de visión a concreción: La reforma fiscal medioambiental en Alemania y las oportunidades para la coordinación europea. In: ÁLVAREZ PELEGRY, Eloy; LARREA BASTERRA, Macarena. Energía y tributación ambiental. Madri: Marcial Pons, 2013. p. 81-98.

BECHARA, Carlos Henrique Tranjan; VARELLA, Ana Luisa Tavares Nobre. A inconstitucionalidade da exigência do ICMS sobre a atividade de extração do petróleo, nos moldes pretendidos pelo Estado do Rio de Janeiro. In: TÔRRES, Heleno Taveira; CATÃO, Marcos André Vinhas. (Coord.). Tributação no Setor do Petróleo. São Paulo: Quartier Latin, 2005. p. 301-321.

BEDER, Sharon. Energia y Poder - La lucha por el control de la electricidad en el mundo. Cidade do México: FCE, 2005. 
BENJAMIN, Herman Antônio. Constitucionalização do ambiente e ecologização da Constituição Brasileira. In: CANOTILHO, José Joaquim Gomes; LEITE, José Rubens Morato (Org.). Direito constitucional ambiental brasileiro. São Paulo: Saraiva, 2007. p. 57-136.

BORGES, Eduardo de Carvalho; LEME, Delvani. (Coord.). Tributação no setor elétrico. São Paulo: Quartier Latin, 2010.

COSTA, Regina Helena. Apontamentos sobre Tributário ambiental no Brasil. In: TORRES, Heleno Taveira (Org.). Direito tributário ambiental. São Paulo: Malheiros, 2005. p. 312-332.

BRASIL. Ministério da Energia. Resenha Energética Brasileira: Exercício de 2012. Disponível em: <http://www.mme.gov.br/mme/ galerias/arquivos/publicacoes/BEN/3_-_Resenha_Energetica/1_Resenha_Energetica.pdf $>$. Acesso em: 6 jun. 2014.

BRASIL. Câmara dos Deputados. Proposta de Emenda Constitucional (PEC) n. 353/2009. Altera os artigos 149, 150, 153, 155, 156, $158 \mathrm{e}$ 161 da Constituição Federal. Disponível em: <http://www.camara. gov.br/proposicoesWeb/prop_mostrarintegra;jsessionid=6C7847DCF 304FC997F2E6114D93F4EC8.node1 codteor $=647044 \&$ filename $=\mathrm{P}$ EC+353/2009>. Acesso em: 30 mar. 2013

BRASIL. Supremo Tribunal Federal. Ação Direta de Inconstitucionalidade n. 3.019 - questionamento da Lei n. 4.117/2003 RJ. Requerente: Procurador Geral da República. Requerido: Governador do Estado do Rio de Janeiro e Assembleia do Estado do Rio de Janeiro. Relator: Ministro Celso de Mello. Brasília, 09.10.2003. Disponível em: $<$ http://www.stf.jus.br/portal/peticaoInicial/verPeticaoInicial.asp?base =A DIN\&s1=3019\&processo=3019> . Acesso em: 24 mar. 2013.

BRASIL. Supremo Tribunal de Justiça. Recurso Especial n. 222.810/ MG - Contrato de Demanda Reservada de Potência da energia elétrica; incidência do ICMS. Recorrente: Semarco Mineração S.A. Recorrido: Fazenda Pública do Estado de Minas Gerais. Relator: Ministro Milton Luiz Pereira. Brasília, 14.03.2000. Disponível em: $<$ https://ww2.stj.jus.br/processo/jsp/ita/abreDocumento.jsp?num registro $=199900618904 \& d t \_p u b l i c a c a 0=15-05-2000 \&$ cod_tipo_ documento=1>. Acesso em: 30 mar. 2013. 
FERRAZ, Roberto. Tributação ambientalmente orientada e as espécies tributárias no Brasil. In: TORRES, Heleno Taveira. (Org.). Direito tributário ambiental. São Paulo: Malheiros, 2005. p. 333-353.

FIORILLO, Celso Antonio Pacheco; FERREIRA, Renata Marques. Curso de direito da energia. São Paulo: Saraiva, 2009.

GAGO RODRÍGUEZ, Alberto; LABANDEIRA VILLOT, Xavier. El papel de los impuestos energéticos-ambientales en la reforma del sistema fiscal español. In: ÁLVAREZ PELEGRY, Eloy; LARREA BASTERRA, Macarena. Energía y tributación ambiental. Madri: Marcial Pons, 2013. p. 169-185.

GALLO, Franco. Las razones del fisco - ética y justicia en los tributos. Barcelona: Marcial Pons, 2011.

GÖRRES, Anselm. Environmental Fiscal Reform: Lessons from the Debate in Germany and Western Europe. In: FALCÓN y TELLA (Dir.). Estudios sobre Fiscalidad de la Energía y Desarrollo Sostenible. Madri: Instituto de Estudios Fiscales, 2006. p. 203-216.

GUTMANN, Daniel. Droit fiscal des affaires. 2. ed. Paris:

Montchrestien - lextenso, 2011.

HERRERA MOLINA, Pedro Manuel. Derecho tributario ambiental. Madri: Marcial Pons, 2000.

LEICESTER, Andrew. Tributación medioambiental: Principios económicos y experiencia en el Reino Unido. In: ÁLVAREZ PELEGRY, Eloy; LARREA BASTERRA, Macarena. Energía y tributación ambiental. Madri: Marcial Pons, 2013. p. 29-66.

LEITE, Antonio Dias. A energia do Brasil. Rio de Janeiro: Elsevier, 2007.

LOUREIRO, Luiz Gustavo Kaercher. Constituição, energia e setor elétrico. Porto Alegre: Sérgio Fabris, 2009.

PIGOU, Arthur Cecil. La Economia del bienestar. Madri: Aguilar, 1946. 
RIBAS, Lídia Maria Lopes Rodrigues. Defesa Ambiental: Utilização de instrumentos tributários. In: TORRES, Heleno Taveira. (Org.). Direito tributário ambiental. São Paulo: Malheiros, 2005. p. 675-723.

ROZAS VALDÉS, José Andrés. Impuestos, energía y derecho comunitário. Revista de la Unión Europea, n. 193. Valencia: Cisspraxis, 2001. p. 73-87.

ROSEMBUJ, Tulio. Los Tributos y la Protecion del meio ambiente. Madri: Marcial Pons, 1995.

SALABERT, Juan Manuel de Remedios; PÉREZ, Yoko Takagi; CANO, Leticia Bueno. Tributación medioambiental en Estados Unidos. In: BECKER, Fernando; CAZORLA, Luis María; MARTÍNEZSIMANCAS, Julían. (Dir.). Tratado de Tributación Medioambiental. v. II. Cizur Menor: Aranzadi, 2008. p. 1.021-1.049.

SILVA. José Afonso da. Direito Ambiental Constitucional. 8. ed. Direito Constitucional Ambiental. São Paulo: Malheiros, 2010.

SILVA, Leonardo Mussi da. ICMS sobre a exploração de petróleo. Rio de Janeiro: Lumen Juris, 2005.

STERLING, Ana Yábar. La necesidad de una Reforma Fiscal Orientada al Fomento del crecimiento sostenible. In: STERLING, Ana Yábar. (Ed.). Fiscalidad ambiental. Barcelona: Cedecs, 1998. p. 25-41.

TAXATION, INNOVATION AND THE ENVIRONMENT. Paris:

Organização para a Cooperação e Desenvolvimento Econômico (OCDE), 2010 . 
Luiz Alberto Blanchet é Doutor e Mestre em Direito pela Universidade Federal do Paraná (1997/1991). Atualmente é Professor do Programa de Pós-gradução da Pontifícia Universidade Católica do Paraná.E-mail: blanchet@blanchet.adv.br. Endereço profissional: Pontifícia Universidade Católica do Paraná, Centro de Ciências Jurídicas e Sociais, Mestrado em Direito Econômico e Social. Rua Imaculada Conceição, 1155, Pós-graduação em Direito. Prado Velho, CEP 80215-901, Curitiba, PR, Brasil.

Edson Luciani de Oliveira é Doutor em Direito Tributário Econômico pela Pontifícia Universidade Católica do Paraná, estágio de doutorado na Universidade de Barcelona - Espanha. E-mail: eluciani@sefa.pr.gov.br.

Endereço profissional: Rua Vicente Machado, 445, $10^{\circ}$ andar, CEP 80420-090, Curitiba, PR, Brasil. 